\title{
Estimating diurnal primate densities using distance sampling method in Moukalaba-Doudou National Park, Gabon
}

\author{
MANGAMA-KOUMBA Lilian Brice ${ }^{1,2, *}$, YOSHIHIRO Nakashima ${ }^{3}$, MAVOUNGOU Jacques François ${ }^{2}$, \\ AKOMO-OKOUE Etienne François ${ }^{2}$, YUMOTO Takakazu ${ }^{4}$,YAMAGIWA Juichi ${ }^{5}$ and M'BATCHI Bertrand ${ }^{1}$ \\ 1 Université des Sciences et Techniques de Masuku (USTM), BP: 901, Franceville-Gabon \\ 2 Institut de Recherche en Écologie Tropicale (IRET-CENAREST), BP: 13354, Libreville-Gabon \\ ${ }^{3}$ College of Bioresource Science, Nihon University, Fugisawa City, Kanagawa 252-0880, Japan \\ ${ }^{4}$ Primate Research Institute, Kyoto University Inuyama, Aichi 484-5806, Japan \\ ${ }^{5}$ Graduate School of Science, Kyoto University, Oiwake-cho, Kitashirakawa, Sakyo-ku, 606-8502 kyoto City, Kyoto, \\ Japan \\ *Corresponding author : MANGAMA KOUMBA Lilian Brice \\ Université des Sciences et Techniques de Masuku (USTM), BP : 901, Libreville-Gabon. E-mail : mangamalilian@yahoo.fr \\ Tel :+2410659 91 77/ 07154745
}

Original submitted in on 19th January 2016. Published online at www.m.elewa.org on $31^{\text {st }}$ March 2016 http://dx.doi.org/10.4314/jab.v99i1.5

\begin{abstract}
Objective: To complete data of diurnal primates, we have estimated the density of diurnal primates in the northeastern part of Moukalaba-Doudou National Park (MDNP) in Gabon and then we compared the results from those obtained in other areas.

Methodology and results: we estimated the densities of each species based on the conventional distancesampling approach. Sampling was done in two sessions along 14 line-transects including various types of vegetation. Cercocebus torquatus is the species most abundance with 62.37 ind.km-2, followed by Cercopithecus nictitans (33.26 individuals. $\mathrm{km}^{-2}$ ), Cercopithecus cephus (29.38 individuals. $\mathrm{km}^{-2}$ ) Lophocebus albigena (15.72 ind. $\mathrm{km}^{-2}$ ). The low density was observed in Cercopithecus pogonias (5.23 individuals. $\mathrm{km}^{-2}$ ). Those values are higher than Makokou with $C$. cephus, $C$. nictitans 25 ind. $\mathrm{km}^{-2}$ and 30 ind. $\mathrm{km}^{-2}$ respectively. Those results are relatively high unlike to Lopé $C$. cephus (5.1 individuals. $\left.\mathrm{km}^{-2}\right) \quad$ C. nictitans $(19.2$ individuals. $\mathrm{km}^{-2}$ ) C. pogonias (4.6 individuals. $\mathrm{km}^{-2}$ ) which have the same vegetation types. They are different from Loango Loango, C. cephus (13.33 individuals. $\mathrm{km}^{-2}$ ) C. nictitans (3.71 individuals. $\mathrm{km}^{-2}$ ) Cercocebus torquatus (15.89 individuals. $\mathrm{km}^{-2}$ ) which have a disturbed forest, which may affect monkey's density.

Conclusion and application: our results showed that the density of monkeys in MDNP is among the highest in Gabon. This can be explained by the lacking of colobine monkeys, which generally dominated in the African rainforest, and the different types of vegetation that we founded.
\end{abstract}

Keywords: Moukalaba-Doudou, distance sampling, monkeys, density, comparison. 


\section{Mangama-Koumba et al. J. Appl. Biosci. $2016 \quad$ Estimating diurnal primate densities using distance sampling method in Moukalaba-Doudou National Park, Gabon}

\section{INTRODUCTION}

Obtaining information on ecology and the status of animal populations from inventory and socioecological studies is a prerequisite for successful wildlife conservation programs. In order to promote early management initiatives, and then invest further efforts efficiently in conservation, wildlife decisionmakers need reliable and profitable estimation of density and abundance of each animal population. Moukalaba-Doudou National Park (MDNP) is one of largest park in Gabon, and is known for its unique fauna and flora of Mt. Doudou (ca. $700 \mathrm{~m}$ above the sea level at the summit) which is supposed to be a Pleistocene refugee (Sossef et al, 2004). MDNP is a mosaic of forest savanna and swamp (Ando et al, 2008; Ebang \& Yamagiwa, 2014), and the study area lacks the colobine monkey, which generally are dominant in the Africans rainforests (Chapman et al. 1999, Matsuda et al. 2013a). This park will be place in an ecotourism project based on western lowland gorillas. Many studies on density, distribution and ecology of medium and large mammals in Moukalaba-Doudou National Park have been done. First, Moukalaba constitute one of the few sites for long-term study of western gorillas (Ando et al. 2008), it is regarded as an important habitat of great apes (Nakashima et al. 2013b), it's also considered a sanctuary of western lowland gorillas because their density is high (Takenoshita \& Yamagiwa, 2008) and it has densities of duikers which are among the highest in African rainforest (Nakashima et al. 2013a). However, no systematic inventory survey of monkeys has been performed. Supplementary information would be important because, monkeys can be an alternative to tourism of great apes in Moukalaba-Doudou National Park. Two types of tools may be used to estimate density of large mammals in tropical forest: "camera trap method" and "distance sampling method" (Karanth \& Nichols, 1998; Silver et al, 2004; Maffei et al, 2004; Core, 1999; Buckland et al, 2001; Rovero \& Marshall, 2009). In camera trap method, the individual place a set of automatic cameras with infrared sensor (Bushnell Trophy Cam 2010) along animal paths within $20 \mathrm{~m}$ of each random point. Each camera within a circle of $20 \mathrm{~m}$ in diameter is located $>100 \mathrm{~m}$ apart from each other. Cameras are set on trees at ca. $30 \mathrm{~cm}$ above ground (Nakashima et al, 2010; Nakashima, 2014). However, in camera trap method we can encounter many difficulties. We cannot obtain information on arboreal primates particularly Cercopithecines monkeys (Whitesides et al., 1988; Hassel-Finnegan et al., 2008; Marshall et al., 2008). In distance sampling method, observers walk along a series of relatively straight transect lines, and record, the perpendicular distance from the line to each object detected or to an estimated centre of the group formed by all objects detected for each encounter in order to estimate the density of objects (Chapman et al, 1988; Buckland et al, 2001). This is a far more suitable method for arboreal and diurnal animals like primates than camera trap method. In Moukalaba-Doudou National Park, there are six species of monkeys, which are Moustached monkey Cercopithecus cephus, Putty-nosed monkey Cercopithecus nictitans, Crowned monkey Cercopithecus pogonias, Ogooue monkey Miopithecus ogoouensis, Red-capped mangabey Cercocebus torquatus and Grey-cheeked mangabey Lophocebus albigena, as nomenclature of primates is following "Les primates d'Afrique Central" (GautierHion et al, 1999). All species are arboreal, except the Red-capped mangabey which are semi-terrestrial. However, the data of density and distribution of arboreal monkeys of Moukalaba-Doudou National Park are unavailable. After many investigations at MDNP, Colobus monkeys are missing due to historical reasons. Great apes are significant due to their high density, the high fruit availability and the density of others frugivorous animals such as duikers is high (Nakashima et al, 2013b; Nakashima, 2015; Takenoshita \& Yamagiwa, 2008). The objective of this paper is to obtain reliable information on monkey's density and their abundance by using the distance sampling methods. The method used will be justified and the results on the density obtained here will be compared with those obtained on others area of Gabon. 


\section{Mangama-Koumba et al. J. Appl. Biosci. $2016 \quad$ Estimating diurnal primate densities using distance sampling method in Moukalaba-Doudou National Park, Gabon}

\section{METHODS}

Study site: The fieldwork was conducted in MoukalabaDoudou National Park in Gabon (Figure 1). The park covers an area of $5,028 \mathrm{~km}^{2}$. We were in the Northeastern part of the Park, which consists of mosaic of forest, savanna, and swamp (Ando et al, 2008; Takenoshita \& Yamagiwa, 2008). We selected ca. 500 $\mathrm{km}^{2}$ of area on the western side of the Moukalaba River as the focal study area. The vegetation is a complex mosaic of a primary forest, a young secondary forest; where Musanga cecropioides dominated, an old secondary forest, savanna and swamp (Iwata \& Ando, 2007). Annual rainfall in this area fluctuated from 1582 $\mathrm{mm}$ to $1886 \mathrm{~mm}$ during 3 years, from 2004 to 2006
(Takenoshita et al., 2008). Which mean monthly the minimum and maximum temperatures ranged from 21.3 to $24.1^{\circ} \mathrm{C}$ and from 29.3 to $33.7^{\circ} \mathrm{C}$, respectively (Takenoshita et al., 2008). There are 2 distinct seasons, a rainy season from October to April and a dry season from May to September. During the 3 months in the middle of the dry season, it seldom rains (Thibault et al., 2004). The forest canopy is approximately $35-45 \mathrm{~m}$ high, and is dominated by Ceasalpiniaceae and Mimosaceae. The understorey was scarce, and shrubs of Dichostemma glaucescens, Meiocarpidium lepidotum, and a large variety of Diospyros species were frequently encountered (Sossef et al. 2004).

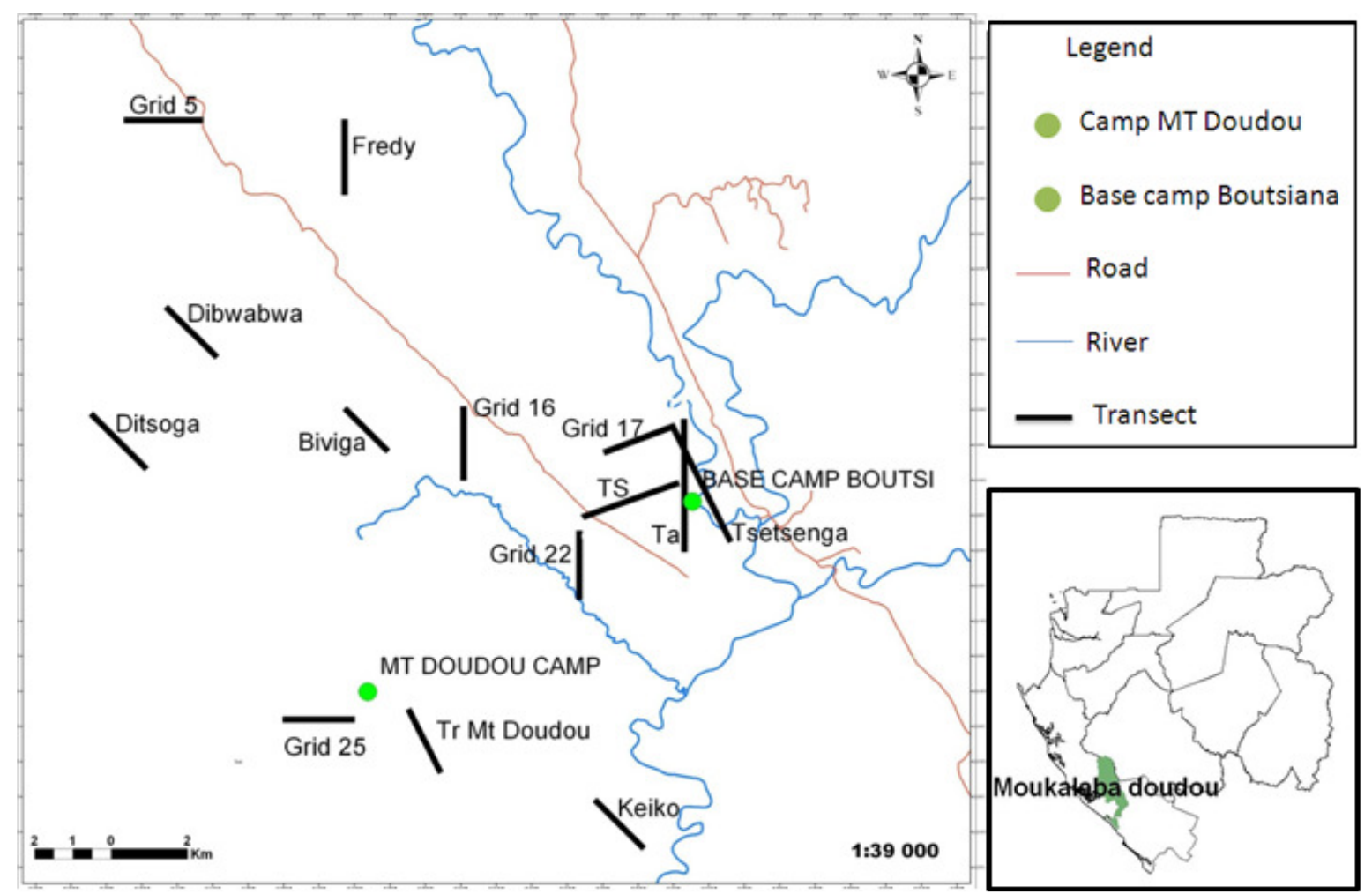

Figure 1: Maps of the North-eastern part of Moukalaba-Doudou National Park

Data collection : The data were collected by line transect census based on distance sampling method (Buckland et al, 1993, 2001).We conducted the censuses on two sessions in 14 transects (table 1). Both sessions census covered the two seasons of the region Moukalaba (dry season and rain season). The first session was from September 2010 to August 2011 and the second session was conducted on August, October, November 2013, February and March 2014. Census was usually carried out in early morning $(7: 30-10: 30)$ and sometimes on late afternoon (15:00 - 17:30) when monkeys were usually active (Mammides et al, 2008). Meteorological aspects were taken into account to avoid the census during the rains. In the first session, we used 5 pre-existing transects (Grid 5, Grid 16, Grid 17, Grid 22 and Grid 25). In the second session, we used 10 transect adjusted to transect (Grid 17, Grid 22 and Grid 25) from the first session. The transect Grid 5 and Grid 16 were not visited during the second session because they were already closed or for logistic reason. All transects were $2 \mathrm{~km}$ long, 


\section{Mangama-Koumba et al. Mangama-Koumba et al. J. Appl. Biosci. 2016 Estimating diurnal primate densities using distance sampling method in Moukalaba-Doudou National Park, Gabon}

excepted transects A, Tsetsenga and $3.5 \mathrm{~km}$ for Ts. All transects were straight, excepted Tsetsenga, which was partially least. Transects near rivers were substantially perpendicular to the rivers except the transect Tsetsenga which interspersed a river base camp. For the first session transect was visited 20 times while at the second session transect was visited 4 times. Therefore, transect Grid 17, Grid 22 and Grid 25 was visited 24 times during those second sessions. During the census, we walked on transects at a speed of $1-1.5 \mathrm{~km} \cdot \mathrm{h}^{-1}$ with a local field assistant while detecting the presence of monkeys on trees. Data collection was made only in two to avoid noise, which could disrupt observation. When a group of monkeys was seen, we recorded the GPS point, the perpendicular distance between the transect and the estimated centre of group seen. The local field assistant recorded the number of individuals. Identification of species monkeys was been made on using "Les primates d'Afrique Central"' (Gautier-hion et al, 1999).

Data analysis : After our data collection, we used a computer software program distance 6.0 (Buckland et al,
1993, 2001) to estimating of density and abundance of monkeys. The data sampled reached enough encounter number for the requirements of analysis in this program, at least $60-80$ encounters are needed for fitting the detection function (cf. Junker et al, 2009). We tested the following issues to four combinations of regular and efficient detection function models (cf. Buckland et al, 1993; Thomas et al, 2010; Leca et al, 2013): 1.uniform key with cosine adjustments; 2.half-normal key with cosine adjustment; 3.half-normal key with hermit polynomial adjustment; and 4.hazard-rate key with simple polynomial adjustment. For our study, we adopted halfnormal and hazard-rate with cosine adjustment. To select the type of detection function model that best fits our data set, we used the following series of criteria (Buckland et al, 1993, 2001; Thomas et al, 2010): 1) the smallest Akaike's Information Criterion (AIC) values 2) the smallest ratio of the $X^{2}$ goodness of fit statistic divided by its degree of freedom; 3 ) a few parameters to avoid large bias but not so many that precision is lost (i.e. the principle of parsimony).

Table 1: List of line transects and encounter rate

\section{Encounter rate}

\begin{tabular}{|c|c|c|c|c|c|c|c|c|}
\hline $\begin{array}{l}\text { Name of } \\
\text { transects }\end{array}$ & $\begin{array}{l}\text { Length } \\
(\mathrm{km})\end{array}$ & 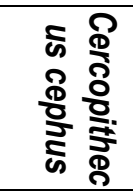 & 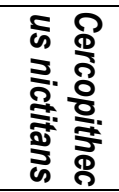 & 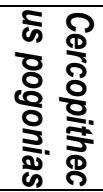 & 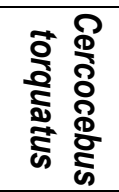 & 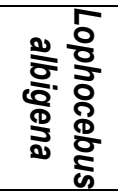 & 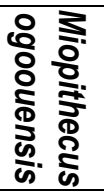 & Forest type \\
\hline A & 4 & 0.32 & 0.188 & 0 & 0.0625 & 0 & 0 & Young Secondary forest \\
\hline Ts & 3.5 & 0.072 & 0 & 0 & 0.143 & 0.143 & 0 & Mixed forest \\
\hline Tsetsenga & 4 & 0.188 & 0.125 & 0 & 0 & 0 & 0.25 & $\begin{array}{l}\text { Musanga dominated } \\
\text { and Riverine forest }\end{array}$ \\
\hline Grid 17 & 2 & 0.65 & 0.5 & 0.1 & 0.25 & 0.25 & 0 & Young Secondary forest \\
\hline Biviga & 2 & 0.125 & 0.25 & 0.125 & 0.25 & 0 & 0 & Swamp forest \\
\hline Fredy & 2 & 0.125 & 0.25 & 0.25 & 0.25 & 0.375 & 0 & Old secondary forest \\
\hline Grid 16 & 2 & 0.25 & 0.63 & 0.075 & 0.225 & 0.175 & 0 & Swamp forest \\
\hline Grid 5 & 2 & 0 & 0.425 & 0.025 & 0.225 & 0.075 & 0 & Old secondary forest \\
\hline Grid 25 & 2 & 0.0625 & 0.25 & 0.083 & 0.16 & 0.33 & 0 & Old secondary forest \\
\hline $\begin{array}{l}\text { Mont- } \\
\text { Doudou }\end{array}$ & 2 & 0.375 & 0.375 & 0.125 & 0 & 0.125 & 0 & Mountain forest \\
\hline Dibwabwa & 2 & 0 & 0.5 & 0.125 & 0.375 & 0.25 & 0 & Old secondary forest \\
\hline Ditsoga & 2 & 0 & 0.5 & 0.25 & 0.125 & 0.25 & 0 & Old secondary forest \\
\hline Grid 22 & 2 & 0.583 & 0.563 & 0.042 & 0.208 & 0.041 & 0.021 & Swamp forest \\
\hline Keiko & 2 & 0.5 & 0.25 & 0 & 0.25 & 0.125 & 0 & $\begin{array}{l}\text { Young } \\
\text { Secondary forest }\end{array}$ \\
\hline Total & 33.5 & 4.151 & 5.056 & 1.2 & 2.649 & 2.264 & 0.271 & \\
\hline
\end{tabular}


We choose of best model on looking for which gives the smallest ratio of goodness in detection function of probability, the density of the group and the group size of each species calculated. In our case, we did not use adjustment terms in the models to avoid implausible, non-

\section{RESULTS}

Estimate the density of monkeys in MoukalabaDoudou National Park: We obtained 359 encounters of monkeys during the census. From the detection function model that best fitted our data, half-normal key was selected for the calculation of monkey's density. The density of different species of monkeys the models of function choired, the density of the group and group size for each species are shown in table 2. The number of encountered of Miopithecus ogoouensis (5 for All transects) was insufficient to calculate the density by monotonic function results (Marques et al, 2007; Nakashima et al, 2013). We compared the results of the densities obtained with those obtained into others study site in Gabon (Lope National Park, Forêt des Abeilles, Loango National Park and Makokou).

distance sampling 6.0. The high density was found in Cercocebus torquatus ( 62.37 ind. $\mathrm{km}^{-2}$ ) with a density of group estimated at 2.71 groups. $\mathrm{Km}^{-2}$, the low density is obtained in Cercopithecus pogonias with 5.23 ind. $\mathrm{km}^{-2}$ and the group size is at 6.99 individuals for 0.74 groups. $\mathrm{km}^{-2}$. Cercopithecus nictitans and Cercopithecus cephus densities are 33.26 ind. $\mathrm{km}^{-2}$ and 29.38 ind. $\mathrm{km}^{-2}$ respectively. Those results suggest that MoukalabaDoudou National Park is among the areas, which possess the highest density of monkeys in central Africa.

Table 2 : Estimated values related to the density of different species monkeys in the North-eastern part of MoukalabaDoudou National Park, as obtained from Distance 6.0.

\begin{tabular}{lcccc}
\hline Species & Density $($ ind.km-2) & Key function & DS & E(S) \\
\hline Cercopithecus cephus & 29.38 & H.N & 3.92 & 7.48 \\
Cercopithecus nictitans & 33.26 & H.N & 5.29 & 6.28 \\
Cercopithecus pogonias & 5.23 & H.N & 0.74 & 6.99 \\
Cercocebus torquatus & 62.37 & H.N & 2.71 & 22.95 \\
Lophocebus albigena & 15.72 & H.N & 1.44 & 10.85 \\
Miopithecus ogoouensis & $*$ & $*$ & $*$ & $*$ \\
\hline
\end{tabular}

${ }^{*}$ Encounter rate is too low to calculate density

H.N: half-normal, H.R: hazard-rate. DS: estimate density of group (number per $\mathrm{km}^{2}$ ); $\mathrm{E}(\mathrm{S})$ : estimate of excepted value (mean) of group size.

Comparison of Moukalaba monkeys density and other study area: Because the number of monkeys encountered to each transect was not large enough to estimate species monkey density of each transect area, we regarded all the transects as a single survey unit representing the north-eastern part of the MoukalabaDoudou National Park. This results have been compared with those obtain in others study area in Gabon as Loango, Lopé, Makokou and foret des Abeilles (Table 3). The densities of monkeys are very high in MoukalabaDoudou, for the two species of guenons present into the entire study site. Excepted for Cercopithecus pogonias
(5.23 individuals. $\mathrm{km}^{2}$ ) which is inferior at Makokou where the densities 22.5 individuals. $\mathrm{km}^{-2}$. Cercocebus torquatus present only in two sites (MDNP and Loango) have a density of 62.37 individuals. $\mathrm{km}^{-2}$ at MDNP, while at Loango National Park we have 15.89 individuals. $\mathrm{km}^{-2}$. Those results shown that MDNP possess the largest populations of Mangabeys (Cercocebus torquatus and Lophocebus albigena) compared to others studies site in Gabon. For the species not present in MDNP Cercopithecus solatus and Colobus satanas, the high densities are observed at Forêt des Abeilles 27.9 individuals. $\mathrm{km}^{-2}$ and 20.5 individuals. $\mathrm{km}^{-2}$ respectively. 


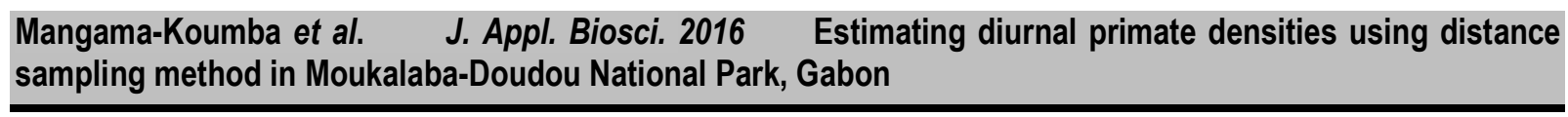

Table 3: Estimating density of North-eastern part of Moukalaba-Doudou National Park with those obtained into others study area, Loango National Park, Lopé National Park, Makokou and Forêt des Abeilles

\section{Density (individuals. $\mathrm{km}^{-2}$ )}

\begin{tabular}{l|c|c|c|c|c|c}
\hline Species & $\begin{array}{c}\text { Moukalaba- } \\
\text { Doudou }\end{array}$ & Loango & Lope & Makokou & $\begin{array}{c}\text { Foret des } \\
\text { Abeilles }\end{array}$ & \\
\hline Cercopithecus nictitans & 33.26 & 3.71 & 19.2 & 30 & 31.8 & \\
Cercopithecus cephus & 29.38 & 13.33 & 5.1 & 25 & 5.8 \\
Cercopithecus pogonias & 5.23 & 5.64 & 4.6 & 22.5 & 5.3 & - \\
Cercocebus torquatus & 62.37 & 15.89 & - & - & 8.4 \\
Lophocebus albigena & 15.72 & 5.23 & 8.1 & - & - \\
Miopithecus ogoouensis & - & - & - & 65 & - \\
\hline
\end{tabular}

Source : Loango (Morgan, 2007); Lopé (Gautier et al, 1997); Makokou (Waser, 1987; Charles-Dominique, 1977; GautierHion, 1978, 1980, 1983); Moukalaba-doudou National Park (this study)

\section{DISCUSSION}

Justification of the choice of method: On analyzing the data collected by distance sampling methods, we asserted that the method used might be good enough to estimate density and abundance of monkeys where they live sympatrically. In theory, it is better to sample a series of random distributed transect within a given area, rather than along pre-existing trails. A permanent human presence may affect the animals behaviour and spatial distribution, and consequently the animal density estimates may be biased (Buckland et al, 2001; Leca et al, 2013). These recommendations in terms of survey design before selecting ours transects are logical, but we have considered many arguments in support of our methodology. First, in practice, non-randomized designs including transects along pre-existing trails, are frequent in primate surveys (Buckland et al, 2001; Hiby \& Krishna, 2001). As long as the number of these transects was sufficient with regard to survey region, the design remains acceptable. Regarding the number of transect selected (14 transects), we confirmed that it was sufficient to made this sampling, and to ensure that they did not pass through the areas with atypical densities. Secondly, the vast majority of transects selected (seven transects) was very far from the village where the human presence is high, and the visits on those transect for others study was made only once by months. Also, it is possible that laying transects along pre-existing trails means that the habitat might not be sampled in a representative manner, because such trails are often placed either on ridges or along waterways, and thus over-or under-sampling some habitat. In response to this argument, we claim that all the types of habitats present on Moukalaba-doudou National Park were sampled by our transects (Table 1), which were therefore representative of entire study area. Finally, during our survey, we obtained well over the minimum number of detections (i.e., 60-80) for the majority species was necessary for fitting the detection function (Barraclough, 2000). In addition, with a minimum number of detections (20-30) it is possible that is why we could not get a Miopithecus ogoouensis density (Nakashima, pers). In this paper, we used two detection function models and we tested the different combinations (Halfnormal and Hazard-rate), the models provided the sensitively similar estimates, which is an additional guarantee of high quality survey information. Overall, we concluded that our survey and data on the abundance of monkeys in Moukalaba-doudou National Park were of sufficient quality to produce reliable estimation of their density in the study area.

Density of monkeys in MDNP and comparison with others study site in Gabon. Our results suggest that monkeys occur at high density in Moukalaba-Doudou National Park. Compared to the density estimates based on others site research, our estimation for Cercocebus torquatus, Cercopithecus nictitans, Cercopithecus cephus and Lophocebus albigena ( 62.37 ind. $\mathrm{km}^{-2}, 33.26$ ind. $\mathrm{km}^{-2}$, 29.38 ind. $\mathrm{km}^{-2}$ and 15.72 ind. $\mathrm{km}^{-2}$ respectively) are among the highest reported from study site in Gabon (Table 3). Cercopithecus pogonias density (5.23 ind. $\mathrm{km}^{-2}$ ) is substantially the same in majority of central Africa site, excepted at Makokou. Many reasons may explain the high densities of monkeys in our study site. First, Moukalaba-Doudou National Park is a large park where they have not colobine monkeys, due to historical reasons and the existence of natural barriers. Indeed, colobine monkeys represent the large group of monkeys where they are presents. They compose the large biomass of primate in Africa (Tashiro, 2002). Therefore, their absence at Moukalaba-Doudou National Park gives to others species of monkeys the opportunity to increase 


\begin{tabular}{l}
$\begin{array}{l}\text { Mangama-Koumba et al. J. Appl. Biosci. } 2016 \quad \text { Estimating diurnal primate densities using distance } \\
\text { sampling method in Moukalaba-Doudou National Park, Gabon }\end{array}$ \\
\hline
\end{tabular}

and in the same occasion decrease the risk of competition. Cercocebus torquatus consume a large variety of foods that they collect on trees (leaves, flowers, fruits and insects), on the ground (fallen fruit, mushrooms, new growths of plant) and by digging litter and soil (rhizomes, tubers, animal preys) or fishing in water (Gautier-Hion \& Gautier, 1978; Gautier-Hion \& Brugière, 2003). Third, the diet of monkeys is composed of $60-80 \%$ of fruits (Gallat et Gallat-Luong, 1985; Buzzard, 2006a, $2006 \mathrm{~b}$ ) and our period of census was during fruit period where the majority of plant species eaten by monkeys tend a bear fruits in peak (Takenoshita et al, 2008). This gives us the possibilities to observe the monkeys, on listening to the fall of fruits caused by monkeys. Finally, Cercopithecus nictitans and Cercopithecus cephus groups are generally constituted of 6 to 20 individuals, and their home range may be 20 to 100 ha according to the number of individual, which compose the group. Therefore, if we consider one group with 6 individuals who represent the mean of individuals by group in Moukalaba-Doudou National Park, in a home range of 20 ha, we can have 30 individuals in 100 ha which represent $1 \mathrm{~km}^{2}$. Our density estimation of $C$. nictitans and $C$ cephus may be certainly the density actual in our study site. To all the area near Moukalaba-Doudou National Park, we obtained different results (table 4). Those finding shows that Moukalaba-Doudou National Park possesses the largest population of Mangabeys compare to other zone. Besides, at Makokou the densities observed with the Guenons were high. The others sites (Loango National Park, Lopé National Park and Forêt des abeilles) have the lowest densities. In fact, the densities and abundances of mammals in a giving region can be explained by many factors. First note that, the presence and absence of different species can have fundamental influences on other aspects of community structure and function (Chapman et al, 1999b). Lopé National Park and Moukalaba-Doudou National Park are a mosaic forest and savanna. They possess the same type of habitat. The result obtained showed the difference in density for the specie present on both sites. This difference is explained by many parameters. The colobine monkeys are present in Lopé National Park where they represent the largest biomass of primate. In this zone, $C$. nictitans is the only species that has a density two times higher than others do. In addition, the presence of seven different species may increase the competition between them. Densities of monkey species in Lopé National Park shown that it is Cercopithecus nictitans and Colobus satanus are most abundant (White, 1994a,b; Tutin et al, 1997). At Loango National Park, which geographically closer to Moukalaba-Doudou National Park, the densities are relatively low. This could be explained by the vegetation type in Loango National Park possesses some disturbed forest (Morgan, 2001). In fact, the disturbed forest is a factor that reduces the animal population that lives in this zone. Loango National Park is also provided of mangrove swamp (Coastal scrub) and only Cercocebus torquatus is subservient to this habitat type (Cooke, 2015; Jones \& Sabater, 1964), which explains a high density for that species at Loango National Park. Makokou and Forêt des Abeilles possess a high density for the Guenons. Particularly for $C$. nictitans, C. cephus and $C$. pogonias at Makokou and $C$. nictitans at forêt des abeilles. Those high densities could be explained at first by the habitat type and the unviability of resource of each species. These three species form many associations polyspecific long term in these areas allowing for equitable distribution of resources and also a best management of the space they share together (Gautier \& Gautier-Hion, 1969). Makokou is a mosaic of dry-land, riparian, and swamp forest, Forêt des Abeilles on the other hand is provided a dense forest at Ceasalpiniaceae. Oates et al (1990) argue that Makokou display high habitat heterogeneity and, habitat heterogeneity tends to increase both the species richness and biomass of primate communities. In addition, in their diet, C. nictitans show a preference at fruit species of Ceasalpiniaceae family present in forêt des abeilles. Those different factors that explain, that we are in presence or not of colobine, abundance or not for the monkeys in that different zone. Finally, in our study, the using of distance sampling showed that MDNP is one study site, which contains the high densities of monkeys in Gabon. Those results are not surprising. Because, more recently, Takenoshita \& Yamagiwa (2008), on using the dung pile count, reported that the densities of gorillas in MDNP was among the highest in protected areas in Central Africa. Although populations densities of Miopithecus ogoouensis is not defined in our study site, they are present and our results suggest that increasing the visit in transect where the species was observed, it would be possible with the same method to determine the density. The previous studies showed that the monkeys and the apes hike a similar density in the area where they are presents but colobine monkey are not present in that zone. It is normal that the densities we had are high in Moukalaba-Doudou National Park. Density of Cercocebus torquatus is may possibly overestimate their actual density. For the best estimate, it will be suitable to use two methods of estimating (camera trap and distance sampling) because $C$. torquatus is semi-terrestrial specie. We suggest that it would be 


Mangama-Koumba et al. J. Appl. Biosci. $2016 \quad$ Estimating diurnal primate densities using distance
sampling method in Moukalaba-Doudou National Park, Gabon

important to conduct studies of guenons and mangabeys of MDNP.

Table 4: Characteristics of different region in Gabon according to vegetation type and diurnal primates

\begin{tabular}{|c|c|c|c|c|}
\hline Region & Vegetation type & $\begin{array}{c}\text { Number of } \\
\text { monkey species }\end{array}$ & $\begin{array}{c}\text { Presence of } \\
\text { Colobine monkeys }\end{array}$ & Source \\
\hline Lopé & $\begin{array}{c}\text { Mature semi- } \\
\text { evergreen forest, a } \\
\text { savanna } \\
\text { and forest-savanna } \\
\text { mosaic }\end{array}$ & 7 & Yes & $\begin{array}{l}\text { Harrison \& Hladik, } \\
\text { 1986; } \\
\text { White et al., 1993; } \\
\text { White, 1994a,b; Tutin } \\
\text { et al, } 1997\end{array}$ \\
\hline Loango & $\begin{array}{l}\text { savanna, swamps } \\
\text { and disturbed and } \\
\text { mature forest }\end{array}$ & 6 & No & \\
\hline Forêt des Abeilles & $\begin{array}{c}\text { Dense forest } \\
\text { dominated by } \\
\text { Caesalpiniaceae }\end{array}$ & 6 & Yes & $\begin{array}{l}\text { (Gautier-Hion et al., } \\
1997\end{array}$ \\
\hline Makokou & $\begin{array}{c}\text { Mature forest is } \\
\text { interspersed with } \\
\text { areas of } \\
\text { riparian and swamp } \\
\text { forest }\end{array}$ & 8 & Yes & $\begin{array}{l}\text { C. M. Hladik, 1973; } \\
\text { Quris, 1976; A. Hladik, } \\
1978\end{array}$ \\
\hline $\begin{array}{l}\text { Moukalaba- } \\
\text { Doudou }\end{array}$ & $\begin{array}{l}\text { Musanga dominated } \\
\text { Riverine forest, } \\
\text { forest-savanna } \\
\text { mosaic and swamp. }\end{array}$ & 6 & No & $\begin{array}{l}\text { (Ando \& Iwata, 2008; } \\
\text { Takenoshita \& } \\
\text { Yamagiwa, 2008; } \\
\text { Takenoshita et al, } \\
\text { 2008; this study) }\end{array}$ \\
\hline
\end{tabular}

\section{ACKNOWLEDGMENTS}

This study was conducted in cooperation among the Centre National de la Recherche Scientifique et Technologique (CENAREST), the Institut des Recherches en Écologie Tropicale (IRET), Université des Sciences et Techniques de Masuku (USTM), Gabon, and Kyoto University, Japan. We thank the Agence Nationale des Parcs Nationaux of the Gabonese government for permission and support for our research project in Gabon. We are also greatly indebted to all of the field assistants at Moukalaba-Doudou National Park and the people in

\section{REFERENCES}

Barraclough, RK. 2000. Distance sampling : a discussion document for the Department of Conservation. Science \& Research Internal Report (175): 1 26. Department of Conservation, Wellington, New Zealand

Buckland, ST, Anderson DR, Burnham KP,. Laake JL. 1993. Distance Sampling: Estimating Abundance of Biological Populations. Chapman \& Hall, London. the villages of Doussala, Konzi, and Mboungou for their kind support and hospitality. This study was financed in part by a Grant-in-Aid for the Doctor Course Program of Masuku University (to L.B MANGAMA KOUMBA), Grants-in-Aid for Scientific Research by the Ministry of Education, Culture, Sports, Science and Technology, Japan (No. 162550080 , No. 19107007, No. 24255010 to J. Yamagiwa), and SATREPS (Science and Technology Research Partnership for Sustainable Development) by JST/JICA, Japan.

Buckland ST, Anderson DR., Burnham KP, Laake JL, Borchers DL. Thomas L. 2001. Introduction to Distance Sampling. Oxford University Press, Oxford.

Bshary R, and Noe R. 1997a. Anti-predator behaviour of red colobus monkeys in the presence of chimpanzees. Behavior. Ecology. Sociobioly 41: 321-333. 


\section{Mangama-Koumba et al. \\ Mangama-Koumba et al. J. Appl. Biosci. 2016 \\ Estimating diurnal primate densities using distance sampling method in Moukalaba-Doudou National Park, Gabon}

Bshary, R, and Noe, R. 1997b. Red colobus and Diana monkeys provide mutual protection against predators. Animal Behavior 54: 1461-1474.

Chapman CA, Gautier-Hion A, Oates JF, Onderdonk DA. 1999b. African primate communities: Determinant of structure and threats to survival. In: Primate communities. Fleagle JG, Janson $\mathrm{CH}$, Reed KE (eds) Cambridge: Cambridge university press, pp. 1-37.

Chapman CA., Balcomb SR., Gillepsie TR., Shorupa, JP, Struhsaker TT. 2000. Long-Term effect on African Primate Communities: a 28-year comparison from Kibale National Park, Uganda. Conservation Biology 14: 207-217.

Chapman CA, Chapman LJ, Cords M,. Gauthua M, Gautier-Hion A, Lambert JE, Rode KD, Tutin CEG, White LJT. 2002. Variation in the diets of Cercopithecus species: Differences within forest, and across species. In: the guenons: Diversity and adaptation in African Monkeys. Glenn and M. Cords (ed). Plenum Press: New York, pp. 319-344.

Charles-Dominique P. 1977. Ecology and Behaviour of Nocturnal Primates: Prosimians of Equatorial West Africa. New York: Columbia University Press.

Galat G, and Galat-Luong A. 1985. "La communauté de primates diurnes de la forêt de Taï, Côte d'Ivoire". Terre Vie 40 : 3-32.

Davies GA. 1994. Colobine populations. In Colobine Monkeys: Their Ecology, Behaviour and Evolution, ed. A. G. Davies \& J. F. Oates, pp. 285-310. Cambridge: Cambridge University Press.

Gartlan JS. and Struhsaker TT. 1972. Polyspoecific associations and niche separation of rain-forest anthropoids in Cameroon, West African. Journal.of Zoology., London., 168: 221266.

Gautier-Hion A., Gautier JP. \& Moungazi A. 1997. Do black colobus in mixed troops benefit from increased foraging efficiency. C. R. Acadamy. Sciences., Paris, 320: 67-71.

Gautier JP. and Gautier-Hion A. 1969. Les associations polyspécifiques chez les Cercopithecidae du Gabon. Revue d'Ecologie (Terre et Vie). 23: 164-201.

Gautier-Hion A. 1971. L'écologie du talapoin du Gabon (Miopithecus talapoin). Revue d'Ecologie. (Terre Vie) 25: 427-490.

Gautier-Hion A and Gautier JP. 1974. les associations polyspécifiques chez les Cercopithèques du plateau de M'Passa, Gabon. Folia primatologica, 22: 134-177.

Gautier-Hion A. 1978. Food niches and coexistence in sympatric primates in Gabon. In Recent Advances in Primatology, Vol. 1. ed. D. J. Chivers \& J. Herbert, pp. 269-86. New York: Academic Press.

Gautier-Hion A and Gautier JP. 1978. Le singe de Brazza: Une stratégie originale. Z. fur Tierspsychol. 46: 84-104.

Gautier-Hion A. 1980. Seasonal variation of diet related to species and sex in a community of Cercopithecus monkeys. Journal of Animal Ecology, 49, 237-69.

Gautier-Hion A. 1983. Leaf consumption by monkeys in western and eastern Africa: A comparison. African Journal of Ecology, 21: 107-113.

Gautier-Hion A. 1988. The diet and dietary habits of forest guenons. In Gautier-Hion, A., Bourliere, F., Gautier, JP., and Kingdon, J. (eds.), A Primate Radiation; Evolutionary Biology of the African Guenons, Cambridge University Press, pp. 257-283.

Gautier-Hion A, Colyn, M, Gautier JP. 1999. Histoire naturelle des primates d'Afrique Centrale. Libreville, Gabon : ECOFAC.

Gautier-Hion A, and Brugière. D. 2003. Significance of Riparian forest for the conservation of Central African Primates. International Journal of Primatology. 26: 515-523.

Hiby, L. and. Krishna. MB. 2001. Line transect sampling from a curving path. Biometrics 57: 727-731.

Iwata Y. and Ando C.2007. Nest and nest-site reuse by western lowland gorillas (Gorilla g.gorilla) in Moukalaba-Doudou National Park, Gabon. Primates. 48: 77-80.

Junker J, N'Goran KP, Kouakou YC, Kühl H. 2009. Biomonitoring guide - Survey training workshop, Taï National Park, Côte d'Ivoire. Great Apes Survival Project / Max Planck Institute / Wild Chimpanzee Foundation.

Leca. JB, Gunst N, Rompis A, Soma G, Arta-Putra IG, Wandia NI. 2013. Population Density and Abundance of Ebony leaf Monkeys (Trachypithecus auratus) in West Bali National Park, Indonesia. Primate Conservation. 26: 133144.

Marshall AR, Lovett JC, White PCL. 2008. Selection of line-transect methods for estimating the density of group-living animals: lessons from the 
primates. American Journal of Primatology. 70: 452-462.

Marques TA, Thomas L, Fancy SG, Buckland ST, Handel CM. 2007. Improving estimates of bird density using multiplecovariate distance sampling. Auk 124:1229-1243.

Morgan BJ. 2007. Group size, density and biomass of large mammals in the Reserve de Faune du Petit Loango, Gabon. African Journal of Ecology. 45: 508-518.

Nakashima. Y., Iwata. Y., Ando. C., Nze Nkogue. C., Inoue E., Akomo-Okoue. E., Mbehang Nguema. P., Diop-Bineni T., Ngok Banak L., Takenoshita. Y., Ngomanda. A., \& Yamagiwa. J. 2013. Assessment of Landscape-Scale distribution of Sympatric Great Apes in African Rainforest Concurrent Use of Nest and camera-Trap surveys. International Journal of Primatology. 9999: 1-11.

Oates JF, Whitesides GH, Davies AG, Waterman PG, Green SM, Dasilva GL, Mole S. 1990. Determinants of variation in tropical forest primate biomass: new evidence from West Africa. Ecology. 71:328-43.

Sosef MSM, Issembe Y, Bourobou HPB, Koopman WJM. 2004. Botanical diversity of the Pleistocene forest refugia Mounts Doudou. In: Fisher BL, editor. Monts Doudou, Gabon : Floral and faunal inventory with reference to elevational distribution. San Francisco, CA: Calofolina Academy of Science. P 17-92.
Struhsaker T. 1975. The Red Colobus Monkey, University of Chicago Press, Chicago.

Takenoshita Y, Ando C, Yamagiwa J. 2008. Fruit phenology of the great ape habitat in the Moukalaba-Doudou National Park, Gabon. African Study Monographs. 39:23-39.

Takenoshita Y and Yamagiwa J. 2008. Estimating gorilla abundance by dung count in the northern part of Moukalaba-Doudou National Park, Gabon. African Study Monographs 39:41-54.

Thomas L, Buckland ST, Rexstad E, Laak JF, Strindberg S, Hedley SL, Bishop JRB, Marques TA, Burnham KP. 2009. Distance 6.0. St Andrews, Scotland, UK: Research Unit for Wildlife Population Assessment, University of St Andrews.

Waser PM. 1987. Interactions among primate species. In Primate Societies. Smuts BB, Cheney DL, Seyfarth RM, Wrangham RW, Struhsaker TT, (ed). Chicago: Chicago University Press pp. 210-26.

Waterman PG, Ross JAM, Bennett EL, Davies AG. 1988. A comparison of the floristics and leaf chemistry of the tree flora in two Malaysian rain forests and the influence of leaf chemistry on populations of colobine monkeys in the Old World. Biological Journal of the Linnean Society, 34, 1-32.

Whitesides GH, Oates JF, Green SM, Kluberdanz RP. 1988. Estimating primate densities from transects in a West African rain forest: a comparison of techniques. J. Anim. Ecol. 57: 345-367. 